\title{
The Distribution and Source Apportionment of 12 heavy metals in a tailing pond, China

\author{
JIE YANG ${ }^{1}$, YUNLONG WANG ${ }^{2}$ AND XIAOHUI GAO ${ }^{2}$
} \\ ${ }^{1}$ College of Water Sciences, Beijing Normal University, Beijing 100875 \\ ${ }^{2}$ College of Water Sciences, Beijing Normal University, Beijing \\ Presenting Author: 18310278705@163.com
}

In this study distribution and source analysis of 12 kinds of heavy metal pollution (As, $\mathrm{Cr}, \mathrm{Mn}, \mathrm{Pb}, \mathrm{V}, \mathrm{Zn}, \mathrm{Cd}, \mathrm{Cu}, \mathrm{Ni}, \mathrm{Tl}, \mathrm{Sb}$, $\mathrm{Hg}$ ) in a tailing pond in Guangxi Province of China was investigated. A total of 129 surface soil samples were collected, including 68 dryland soil samples, 29 paddy soil samples, and 32 other types of soil samples.

According to the statistical analysis of heavy metal content in rock samples, $\mathrm{As}, \mathrm{Pb}, \mathrm{Zn}, \mathrm{Cd}, \mathrm{V}$ and $\mathrm{Sb}$ were excessive elements, while other heavy metals $(\mathrm{Cr}, \mathrm{Ni}, \mathrm{Hg}, \mathrm{Mn}, \mathrm{Cu}$ and $\mathrm{Tl}$ ) were close or lower than the risk control standard for soil contamination of agricultural land of China. The vertical distribution of various heavy metals in soil profile was quite different. The nugget coefficient of heavy metals (As, Mn, V, Zn, Cd and Ni) was less than $25 \%$, indicating that the spatial variability had a greater relationship with natural factors such as soil parent material. While to the other heavy metals, their nugget coefficient were between $25 \%$ and $75 \%$, and the spatial correlation was subject to the interaction of natural and human factors. The Kriging interpolation results showed that the entire study area might have the risk of $\mathrm{Cd}$ and $\mathrm{Sb}$ pollution, and heavy metals $\mathrm{As}, \mathrm{Pb}, \mathrm{V}$ and $\mathrm{Zn}$ pollution risk area accounted for more than half of the total area.

Spearman correlation analysis results demonstrated that most of the heavy metals were highly correlated, and there was a greater possibility of heavy metal compound pollution in study area. Results of principal component analysis indicated that the first principal component mainly reflected the accumulation of heavy metals ( $\mathrm{As}, \mathrm{Pb}, \mathrm{Zn}, \mathrm{Cd}$ and $\mathrm{Sb}$ ), with a contribution rate of $58.10 \%$, which might represent anthropogenic sources of mining activities such as waste water discharge and transportation. The contribution rate of the second principal component was $12.37 \%$, and the source of $\mathrm{V}$ might be related to factors such as mining and water interaction. Besides the contribution rate of the third principal component was $11.68 \%$. It was speculated that $\mathrm{Ni}$ originated from soil parent materials. 